\title{
Effects of Epigallocatechin Gallate on Tert-Butyl Hydroperoxide-Induced Mitochondrial Dysfunction in Rat Liver Mitochondria and Hepatocytes
}

\author{
Vojtech Mezera, ${ }^{1,2}$ Rene Endlicher, ${ }^{3}$ Otto Kucera, ${ }^{1}$ Ondrej Sobotka, ${ }^{1}$ \\ Zdenek Drahota, ${ }^{1}$ and Zuzana Cervinkova ${ }^{1}$ \\ ${ }^{1}$ Department of Physiology, Faculty of Medicine in Hradec Kralove, Charles University in Prague, \\ 50038 Hradec Kralove, Czech Republic \\ ${ }^{2}$ Buck Institute for Research on Aging, Novato, CA 94945, USA \\ ${ }^{3}$ Department of Anatomy, Faculty of Medicine in Hradec Kralove, Charles University in Prague, 50038 Hradec Kralove, Czech Republic
}

Correspondence should be addressed to Vojtech Mezera; vmezera@buckinstitute.org

Received 7 September 2016; Accepted 3 November 2016

Academic Editor: Taofeek O. Ajiboye

Copyright (c) 2016 Vojtech Mezera et al. This is an open access article distributed under the Creative Commons Attribution License, which permits unrestricted use, distribution, and reproduction in any medium, provided the original work is properly cited.

\begin{abstract}
Epigallocatechin gallate (EGCG) is a green tea antioxidant with adverse effects on rat liver mitochondria and hepatocytes at high doses. Here, we assessed whether low doses of EGCG would protect these systems from damage induced by tert-butyl hydroperoxide (tBHP). Rat liver mitochondria or permeabilized rat hepatocytes were pretreated with EGCG and then exposed to tBHP. Oxygen consumption, mitochondrial membrane potential (MMP), and mitochondrial retention capacity for calcium were measured. First, $50 \mu \mathrm{M}$ EGCG or $0.25 \mathrm{mM}$ tBHP alone increased State 4 Complex I-driven respiration, thus demonstrating uncoupling effects; $\mathrm{tBHP}$ also inhibited State 3 ADP-stimulated respiration. Then, the coexposure to $0.25 \mathrm{mM}$ tBHP and $50 \mu \mathrm{M}$ EGCG induced a trend of further decline in the respiratory control ratio beyond that observed upon tBHP exposure alone. EGCG had no effect on MMP and no effect, in concentrations up to $50 \mu \mathrm{M}$, on mitochondrial calcium retention capacity. tBHP led to a decline in both MMP and mitochondrial retention capacity for calcium; these effects were not changed by pretreatment with EGCG. In addition, EGCG dosedependently enhanced hydrogen peroxide formation in a cell- and mitochondria-free medium. Conclusion. Moderate nontoxic doses of EGCG were not able to protect rat liver mitochondria and hepatocytes from tBHP-induced mitochondrial dysfunction.
\end{abstract}

\section{Introduction}

Epigallocatechin gallate (EGCG) is an important polyphenolic compound of green tea $[1,2]$. It was repeatedly reported that EGCG acts as a cytoprotective agent [3-5]. EGCG can exert its antioxidant properties by several different mechanisms. First, EGCG can be oxidized on some of its phenolic groups, thereby generating a quinone [6]. Second, EGCG is able to activate the stress-responding transcription factor Nrf2 [2, 7]. Third, EGCG can have uncoupling effects, [8] and mild uncoupling is able to attenuate production of mitochondrial reactive oxygen species (ROS) $[9,10]$.

In contrast, high doses of EGCG were found to be hepatotoxic [8, 11-13]. Similarly, EGCG displayed toxicity on mitochondria in permeabilized hepatocytes [8] and on mitochondria in a hepatoma cell line [14]. Long-term treatment of mice with tea-based beverage was reported to downregulate the expression of mitochondrial respiratory complexes [15]. A protective effect on mitochondria from different organs was reported in other studies [16-18]. The resulting effect of EGCG depends not only on the dose but also on the type of stress exposure [19]. For example, EGCG is able to directly scavenge superoxide [20] but can promote production of hydrogen peroxide $[21,22]$.

Thus, we decided to test whether low concentrations of EGCG would alter mitochondrial dysfunction caused by tert-butyl hydroperoxide (tBHP). tBHP is an oxidative agent which affects cellular glutathione in a similar manner as 
hydrogen peroxide but is not degraded by catalase [23]. tBHP is able to inhibit Complex I-driven respiration in mitochondria, as well as some oxoacid dehydrogenases [2426]. Interestingly, tBHP does not have a major effect on succinate dehydrogenase [24], which is instead susceptible to the action of superoxide [27].

Other authors found that EGCG ameliorated tBHPinduced oxidative damage in liver homogenates [1] and in hepatoma cell lines $[28,29]$. In addition, tea extract but not EGCG alone was able to ameliorate tBHP-induced cell death in primary rat hepatocytes [30]. The effects of EGCG and tBHP on liver mitochondrial function have not yet been tested and will be the focus of the present study in two experimental models: permeabilized rat hepatocytes and isolated rat liver mitochondria. As will be shown by measurements of respiration, mitochondrial membrane potential, and calcium retention capacity, low concentrations of EGCG did not affect mitochondrial parameters but did not alter tBHP-induced mitochondrial dysfunction either. Furthermore, high concentrations of EGCG were even found to enhance the toxicity of tBHP.

\section{Materials and Methods}

2.1. Chemicals. Unless otherwise stated, all chemicals including EGCG and tBHP were of analytical grade and purchased from Sigma-Aldrich (Madison, WI, USA). Collagenase NB4 was obtained from SERVA Electrophoresis (Germany).

2.2. Animals. Male Wistar rats (220-320 g body weight) were purchased from Velaz (Lysa nad Labem, Czech Republic). All the animals received humane care, water, and a standard laboratory diet ad libitum. All the procedures were performed under general anesthesia. The study protocols were approved by the Animal Welfare Body of the Faculty of Medicine in Hradec Kralove (approving protocol number MSMT44579/2014-3).

2.3. Preparation of Permeabilized Hepatocytes. The hepatocytes were isolated by two-step collagenase perfusion as described previously [8]. Briefly, the portal vein was cannulated and the liver was perfused with a calcium-free solution and then with a solution containing collagenase. The excised digested liver was then mechanically disrupted. The resulting suspension was centrifuged three times at $28 \times \mathrm{g}$ to separate hepatocytes from other cell types. The viability of the cells was verified using a Trypan Blue exclusion test. Viability of $>90 \%$ was required for further analyses.

The cells were diluted to a final density of 125,000 cells per $\mathrm{mL}$ [31]. Cells were permeabilized in an oxygraph chamber by digitonin addition $(10 \mu \mathrm{g} / \mathrm{mL})$.

2.4. Mitochondrial Isolation. Mitochondria were isolated as described previously $[32,33]$. Briefly, the liver was cut into small pieces and homogenized using an Ultra Turrax T8 homogenizer (IKA Laboratortechnik, Staufen, Germany) in homogenization medium containing $220 \mathrm{mM}$ D-mannitol, $70 \mathrm{mM}$ sucrose, $2 \mathrm{mM}$ HEPES, $0.2 \mathrm{mM}$ EGTA, pH 7.2, and $0.05 \%(\mathrm{w} / \mathrm{v})$ fat-free bovine serum albumin. The $10 \%$ homogenate was centrifuged at $830 \times \mathrm{g}$ for $4 \mathrm{~min}$ at $4^{\circ} \mathrm{C}$. The resulting supernatant was purified by filtration through gauze. After further repeated centrifugation at $10,000 \mathrm{~g}$ for $15 \mathrm{~min}$, the sediment was collected and resuspended in a medium without EGTA. The isolated mitochondria were then stored at $4^{\circ} \mathrm{C}$ until analyses for a maximum duration of 5 hours. The mitochondrial content was normalized to protein concentration, which was determined using the Bradford method with bovine serum albumin as a standard [34].

2.5. Respirometry. Oxygen consumption was measured in permeabilized hepatocytes and in isolated mitochondria by high resolution respirometry using a High Resolution Oxygraph 2K (OROBOROS INSTRUMENTS, Innsbruck, Austria) according to manufacturer's instructions. First, the suspensions of permeabilized hepatocytes $(125,000$ cells per $\mathrm{mL}$ ) or isolated mitochondria $(0.15 \mathrm{mg}$ protein per $\mathrm{mL}$ ) were exposed to various concentrations of EGCG (medium only, 2, 10, and $50 \mu \mathrm{M}$ ) for 5 minutes and then to $0.25 \mathrm{mM}$ tBHP for another $5 \mathrm{~min}$. Next, $10 \mathrm{mM}$ glutamate and $2.5 \mathrm{mM}$ malate $(\mathrm{G}+\mathrm{M})$ were added as substrates for Complex I to measure leak respiration (State 4 ). Then, $1.5 \mathrm{mM}$ adenosine diphosphate (ADP) was added to evaluate the capacity of oxidative phosphorylation (State 3). Afterwards, $20 \mu \mathrm{M}$ cytochrome $\mathrm{c}$ was used to test the outer mitochondrial membrane integrity [35]. Then, $1 \mu \mathrm{M}$ rotenone (Rot) was added to inhibit Complex I, and $10 \mathrm{mM}$ succinate (Suc) was provided as a substrate for Complex II. The respiratory control ratio was calculated as a ratio of State 3 (oxygen consumption in the presence of $\mathrm{G}+\mathrm{M}+\mathrm{ADP}$ ) to State 4 (leak oxygen consumption with $\mathrm{G}+\mathrm{M}$ only) [36]. The respiration data are expressed as percent of controls (respiration after addition of $\mathrm{G}+\mathrm{M}$ ) to normalize for any interindividual differences in the mitochondrial preparations. The data were analyzed by the Oroboros DatLab 6.1 (OROBOROS INSTRUMENTS, Innsbruck, Austria) software.

2.6. Mitochondrial Membrane Potential. The measurement of mitochondrial membrane potential (MMP) was performed as described previously [37], with the exception that safranine $\mathrm{O}$ was used in the present study. Safranine $\mathrm{O}$ is a charged dye that stacks in mitochondria with high MMP, thereby decreasing its levels in the medium. Conversely, low MMP leads to an efflux of safranine $\mathrm{O}$ from mitochondria and its increased concentration in the medium [38]. First, the cuvette was filled with $1 \mathrm{~mL}$ of medium containing $80 \mathrm{mM} \mathrm{KCl}, 10 \mathrm{mM}$ Tris- $\mathrm{HCl}, 3 \mathrm{mM} \mathrm{MgCl} 2,4 \mathrm{mM} \mathrm{K}_{3} \mathrm{PO}_{4}, 1 \mathrm{mM}$ EDTA, $\mathrm{pH} 7.2$, $10 \mu \mathrm{M}$ safranine $\mathrm{O}$, and, in indicated cases, also EGCG. Then, hepatocytes or mitochondria $(0.1 \mathrm{mg}$ protein per $\mathrm{mL}$ ) were added. As substrates, we used glutamate $(10 \mathrm{mM})$ and malate (2.5 mM). Afterwards, tBHP was added. As a last step, $10 \mu \mathrm{M}$ protonophore FCCP was added to dissipate MMP. We used an AMINCO-Bowman Series 2 Luminescence Spectrometer (Thermo Fisher Scientific, Waltham, MA, USA) for the measurement of fluorescence with an excitation wavelength of $495 \mathrm{~nm}$ and an emission wavelength of $586 \mathrm{~nm}$.

2.7. Calcium Retention Capacity. Mitochondrial retention capacity for calcium was evaluated using the fluorescent 
probe Calcium Green (Thermo Fisher Scientific) on an AMINCO-Bowman Series 2 spectrometer with the following parameters: excitation wavelength $506 \mathrm{~nm}$ and emission wavelength $592 \mathrm{~nm}$. Briefly, swelling medium $(125 \mathrm{mM}$ saccharose, $65 \mathrm{mM} \mathrm{KCl}, 10 \mathrm{mM}$ HEPES, and $\mathrm{pH} 7.2$ [39]), $1 \mu \mathrm{M}$ Calcium Green, $10 \mathrm{mM}$ succinate, and mitochondria $(0.4 \mathrm{mg}$ protein per $\mathrm{mL}$ ) were added to a cuvette. Afterwards, calcium chloride $\left(\mathrm{CaCl}_{2}\right)$ was titrated; its concentration was increased by $1.25 \mu \mathrm{M}$ with every addition. In indicated cases, EGCG was added 5 minutes prior to the addition of tBHP. The probe reversibly binds to calcium ions. When mitochondria accumulate calcium, the fluorescent signal in the medium decreases $[40,41]$. When the retention capacity is exceeded, mitochondria release the accumulated calcium and the fluorescence rises dramatically.

2.8. Hydrogen Peroxide Production. The rate of hydrogen peroxide production by EGCG was measured in the absence of any biological sample at $37^{\circ} \mathrm{C}$ by an $\mathrm{O} 2 \mathrm{k}$-Fluorometer (OROBOROS INSTRUMENTS, Innsbruck, Austria) [42]. The light intensity of the LEDs was set to a polarization voltage of $500 \mathrm{mV}$ in the presence of $10 \mu \mathrm{M}$ Amplex Red (Life Technologies) and horseradish peroxidase (HRP; $1 \mathrm{IU} / \mathrm{mL}$ ). Briefly, hydrogen peroxide reacts with Amplex Red in the presence of HRP creating the fluorescent product resorufin. The rate of hydrogen peroxide production was calculated as a first derivation of the resorufin levels over time. The calibrations were performed by $\mathrm{H}_{2} \mathrm{O}_{2}$ titrations in steps of $0.1 \mu \mathrm{M}$ at the beginning and throughout the whole measurement after each EGCG addition to eliminate possible interference of EGCG with Amplex Red assay, which was described before [43]. Due to the antioxidant properties of EGCG, we were not able to calibrate the signal at concentrations of EGCG higher than $20 \mu \mathrm{M}$; therefore, the sensitivity of our $\mathrm{H}_{2} \mathrm{O}_{2}$ measurements was limited by this EGCG concentration.

2.9. Statistical Analysis. The respiration data are based on six or more biological replicates (i.e., with at least six individual animals), and calcium retention capacity measurements are based on three biological replicates; mitochondrial membrane potential represents data from a single preparation. Software GraphPad Prism 6.01 (GraphPad Software, La Jolla, CA, USA) was used for the calculations. First, normality was tested by means of the Kolmogorov-Smirnov test. Oneway ANOVA or its nonparametric variant the Kruskal-Wallis test was used to analyze differences among groups, and Tukey's posttest and Dunn's posttest were used for multiple comparisons. $p<0.05$ was considered significant.

\section{Results}

3.1. Mitochondrial Respiration: Effect of tBHP and EGCG. Representative curves of mitochondrial respiration in isolated mitochondria are provided in Figure 1. State 4 respiration increases only slightly after the addition of substrates for Complex I because the availability of adenosine diphosphate (ADP) is very low. Respiration increases rapidly after the addition of ADP (State 3). Rotenone was then added to

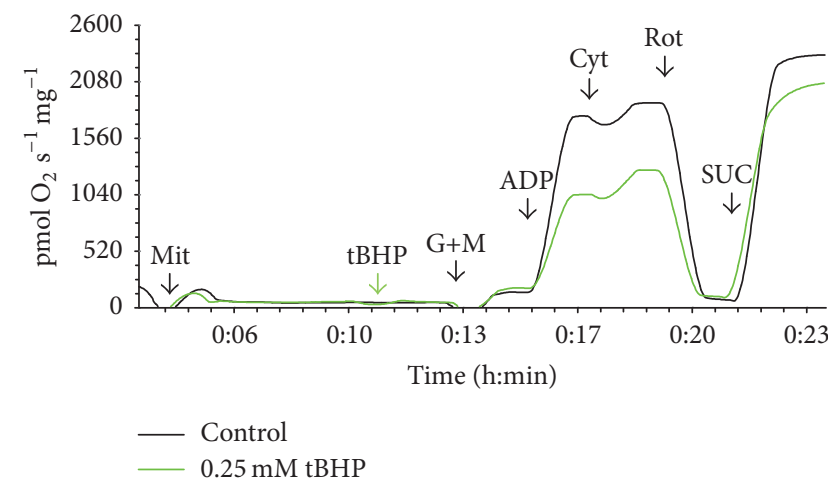

FIGURE 1: Representative curves of the oxygen consumption ratio in control isolated mitochondria (black curve) and mitochondria exposed to $0.25 \mathrm{mM}$ tBHP (green curve). Additions are marked at the $X$-axis: Mit $=$ mitochondria $(0.15 \mathrm{mg}$ protein per $\mathrm{mL}), \mathrm{tBHP}=$ $0.25 \mathrm{mM}$ tBHP, $\mathrm{G}+\mathrm{M}=10 \mathrm{mM}$ glutamate and $2.5 \mathrm{mM}$ malate, ADP $=1.5 \mathrm{mM}$ adenosine diphosphate, $\mathrm{Cyt}=20 \mu \mathrm{M}$ cytochrome $\mathrm{c}$, ROT $=1 \mu \mathrm{M}$ rotenone, and SUC $=10 \mathrm{mM}$ succinate.

suppress glutamate- and malate-stimulated respiration via inhibition of mitochondrial Complex I. Finally, the addition of succinate provides electrons for mitochondrial Complex II, therefore bypassing the blocked Complex I and resulting in State 3 succinate-stimulated respiration. The exposure to $0.25 \mathrm{mM}$ tBHP led to blunting of the observed increase in State 3 respiration of Complex I ( $p<0.001$, Figure 2(c)), but Complex II respiration was not significantly changed.

After exposure to various concentrations of EGCG and/or tBHP, similar effects were observed in isolated mitochondria and in permeabilized hepatocytes: the State 4 leak respiration in the presence of substrates for Complex I but without ADP was increased by the addition of $0.25 \mathrm{mM}$ tBHP in both isolated mitochondria $(p<0.01)$ and in permeabilized hepatocytes $(p<0.05)$. Treatment with EGCG at a concentration of $50 \mu \mathrm{M}$ led to a higher level of State 4 leak respiration in isolated mitochondria ( $p<0.001$ versus controls) and enhanced the tBHP-induced increase $(p<0.001$ versus tBHP alone); these differences did not reach statistical significance in permeabilized hepatocytes (Figure 2).

The respiratory control ratio, calculated as the ratio of State 3 (glutamate + malate + ADP) to State 4 (glutamate + malate) respiration [44], was significantly lower in mitochondria treated with tBHP than in controls $(p<0.001$ for both isolated mitochondria and permeabilized hepatocytes). The addition of EGCG at a concentration of $50 \mu \mathrm{M}$ led to a lower respiratory control ratio than in controls $(p<$ 0.001 in isolated mitochondria, $p<0.05$ in hepatocytes). In addition, $50 \mu \mathrm{M}$ EGCG potentiated the decrease in the respiratory control ratio caused by $0.25 \mathrm{mM} \mathrm{tBHP}$ in isolated mitochondria (Table 1). These findings point to a suppression of spare respiratory capacity by the combination of both compounds.

3.2. Mitochondrial Membrane Potential. The concentration of tBHP used for the suppression of mitochondrial respiration, $0.25 \mathrm{mM}$, did not confer any changes in mitochondrial 
TABLE 1: Respiratory control ratio.

\begin{tabular}{lcccccccc}
\hline Treatment & Control & EGCG2 & EGCG10 & EGCG50 & tBHP0.25 & EGCG2 + t-BHP0.25 & EGCG10 + tBHP0.25 & EGCG50 + tBHP0.25 \\
\hline Mit & $11.6 \pm 1.3$ & $10.5 \pm 1.1$ & $10.0 \pm 0.9$ & $7.0 \pm 1.1^{* * *}$ & $6.3 \pm 0.9^{* * *}$ & $5.8 \pm 0.7^{* * *+++}$ & $5.9 \pm 0.2^{* * *++++}$ & $4.4 \pm 0.3^{* * *+++,+}$ \\
Hep & $5.5 \pm 1.1$ & $5.1 \pm 1.0$ & $5.2 \pm 0.8$ & $4.2 \pm 0.6^{*}$ & $3.3 \pm 0.5^{* * *}$ & $3.2 \pm 0.6^{* * *+++}$ & $3.3 \pm 0.6^{* *,+++}$ & $2.7 \pm 0.5^{* * *+}$ \\
\hline
\end{tabular}

${ }^{1}$ Data are expressed as the mean \pm standard deviation. Mit $=$ mitochondria and Hep = permeabilized hepatocytes. Concentration of $\mathrm{tBHP}$ is shown in $\mathrm{mmol} / \mathrm{L}$ and that of EGCG in $\mu \mathrm{mol} / \mathrm{L} ; *$ versus control, + versus corresponding EGCG, and \# versus tBHP alone; $p<0.05,<0.01$, or $<0.001$ for one, two, or three symbols, respectively; $n=6-10$.

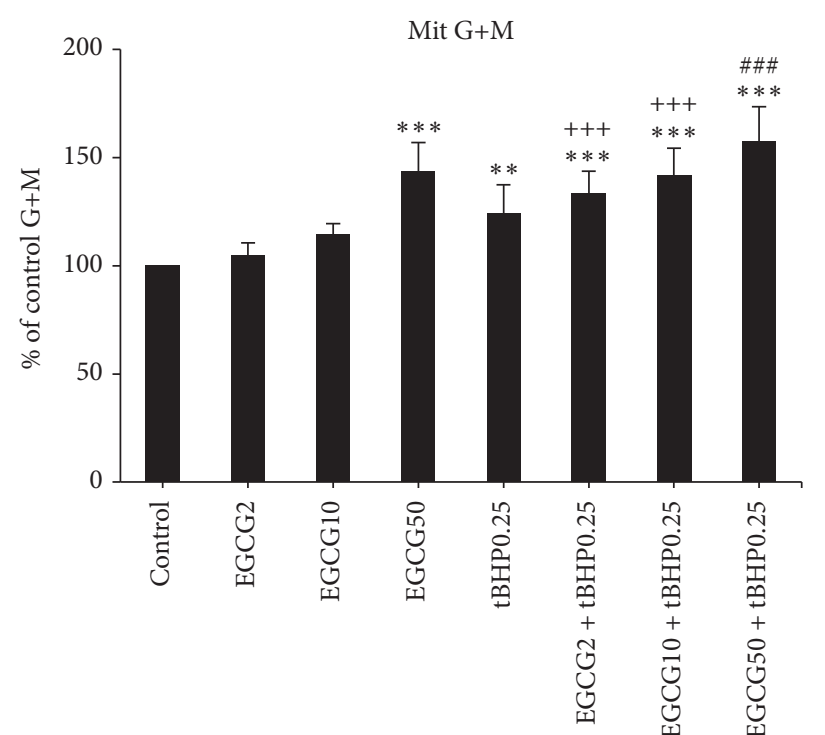

(a)

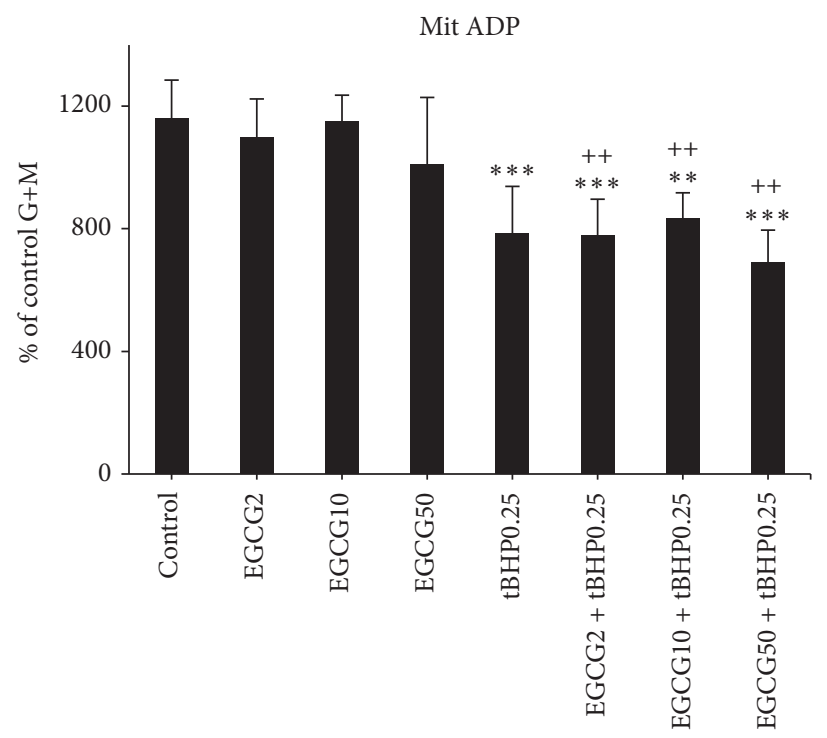

(c)

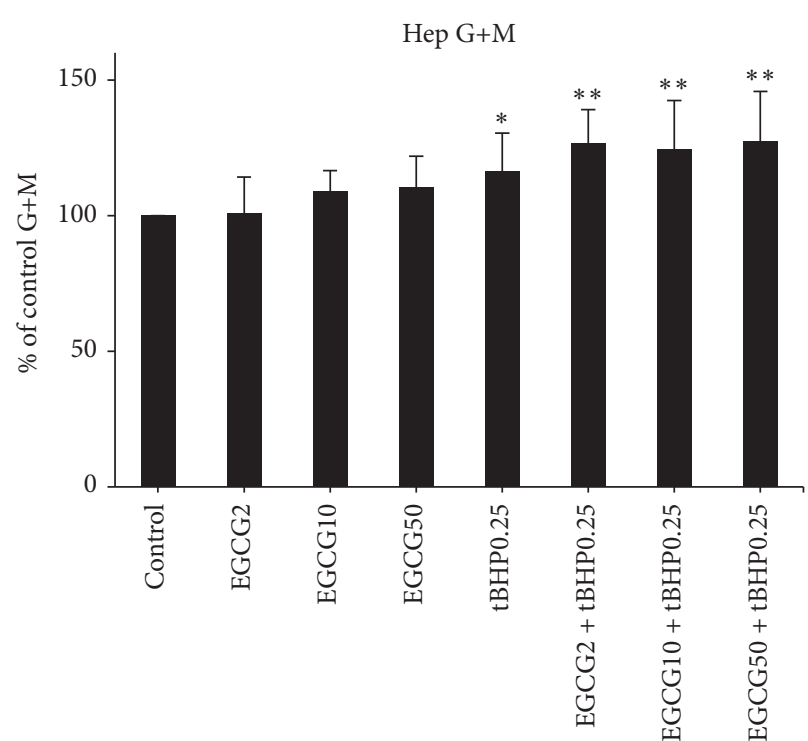

(b)

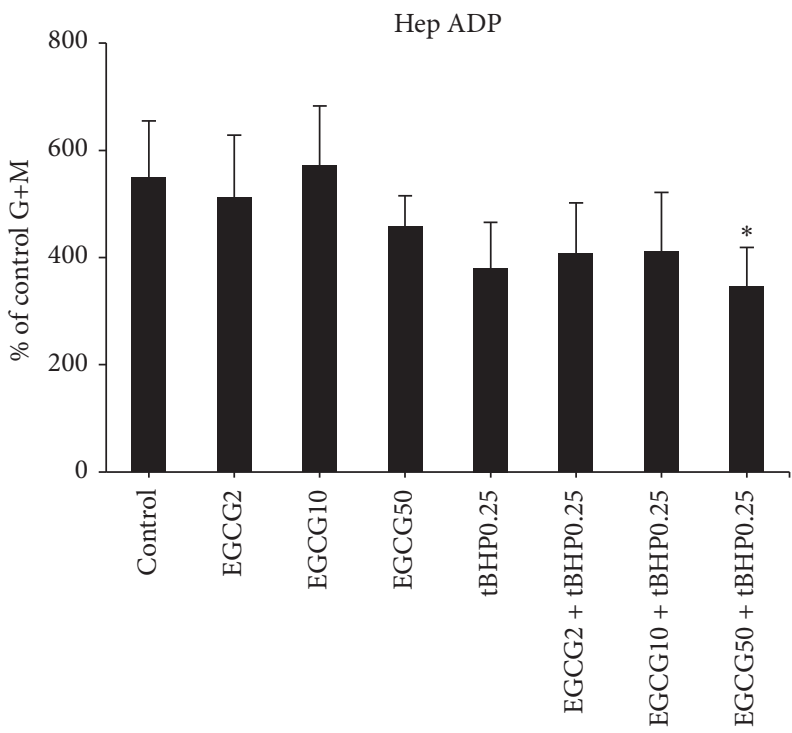

(d)

FIGURE 2: Respiration with glutamate and malate after exposure to EGCG and/or tBHP. (a) Leak respiration in isolated mitochondria; (b) leak respiration in permeabilized hepatocytes; (c) ADP-stimulated respiration in isolated mitochondria; (d) ADP-stimulated respiration in permeabilized hepatocytes. The concentrations of EGCG are expressed in $\mu \mathrm{mol} / \mathrm{L}$, and those of tBHP are in mmol/L. * versus control, + versus corresponding EGCG alone, \# versus tBHP alone; $p<0.05,<0.01$, or $<0.001$ for one, two or three symbols, respectively; $n=6-10$. 


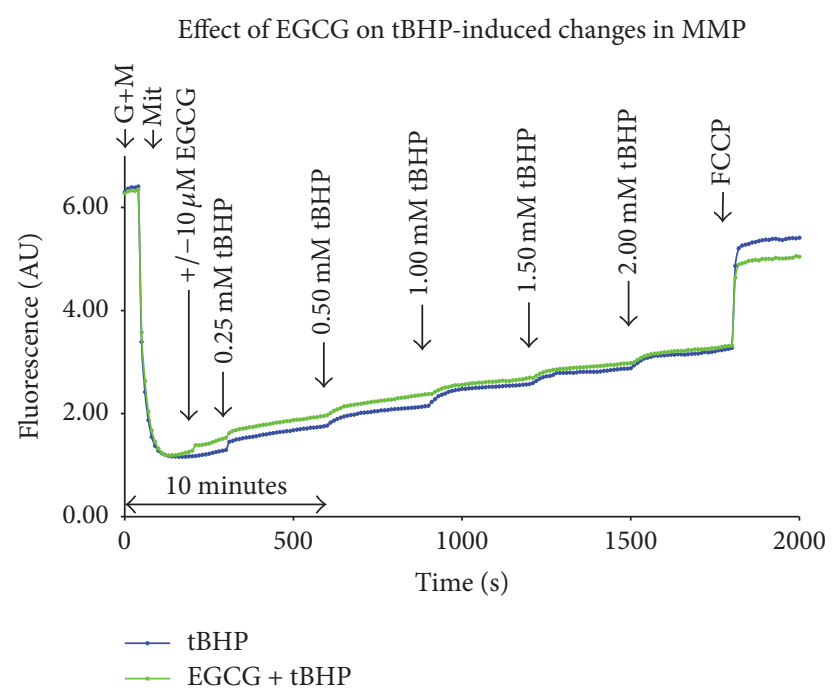

FIGURE 3: Representative curves of MMP measurement using safranine $\mathrm{O}$ after treatment with EGCG and/or tBHP. The results from titration of tBHP with and without EGCG pretreatment are shown. $\mathrm{AU}=$ Arbitrary Units, $\mathrm{G}+\mathrm{M}=$ glutamate $(10 \mathrm{mM})$ and malate $(2.5 \mathrm{mM})$, and $\mathrm{Mit}=$ mitochondria $(0.1 \mathrm{mg}$ protein per $\mathrm{mL})$.

membrane potential (MMP). Higher doses of tBHP, up to $2 \mathrm{mM}$, were necessary to see a drop in MMP. Mitochondria preincubated with $10 \mu \mathrm{M}$ EGCG and then treated with tBHP at concentrations of 0.25 to $2 \mathrm{mM}$ displayed the same changes in MMP as mitochondria treated with tBHP alone (Figure 3).

3.3. Mitochondrial Calcium Retention Capacity. EGCG alone had no effect on mitochondrial calcium retention capacity in concentrations of $50 \mu \mathrm{M}$ and lower. Exposure to $100 \mu \mathrm{M}$ EGCG decreased retention capacity of mitochondria to $71.4 \%$ of controls (Figure 4(a)). Treatment with tBHP led to a decline in mitochondrial retention capacity for calcium, illustrated by an early increase in fluorescence following the addition of $\mathrm{CaCl}_{2}$. These results were not significantly changed by pretreatment with EGCG (Figure 4(b)).

\subsection{Oxygen Consumption and Hydrogen Peroxide Produc-} tion with EGCG. To investigate whether EGCG also forms hydrogen peroxide in our respiratory medium, we performed background measurements in the absence of any biological sample. We found a linear relationship between $\mathrm{H}_{2} \mathrm{O}_{2}$ production and EGCG concentration (Figure 5(a)). By employing unique simultaneous measurements of high resolution respirometry and fluorometry, we also detected a linear increase in oxygen consumption caused by EGCG itself (Figure 5(b)). Increased oxygen consumption was also found in the absence of Amplex Red and HRP (Figure 5(c)), suggesting that the results were not solely caused by redox-active chemicals present in the medium during $\mathrm{H}_{2} \mathrm{O}_{2}$ measurement (Amplex Red and/or HRP).

\section{Discussion}

The exposure of both isolated mitochondria and permeabilized hepatocytes to $0.25 \mathrm{mM}$ tBHP led to an inhibition of
Complex I-stimulated respiration. This is in accord with our previous findings $[25,31]$ and provides further validation of this model.

Pretreatment with low dose of EGCG $(10 \mu \mathrm{M})$ did not modify the subsequent $\mathrm{tBHP}$-induced mitochondrial dysfunction. The additive decline in the respiratory control ratio in both systems with $50 \mu \mathrm{M}$ EGCG and $0.25 \mathrm{mM}$ tBHP can be interpreted as a decrease in maximal phosphorylation capacity and an additional uncoupling of oxidative phosphorylation beyond those caused by $\mathrm{tBHP}$ alone.

An uncoupling effect is not necessarily deleterious-mild uncoupling is able to lower the mitochondrial electrochemical gradient, attenuate ROS production, and limit further oxidative damage $[9,10]$. Uncoupling dissipates the proton motive force and decreases the ROS formation at Complex I during reverse electron transport [45]. This may explain the lack of protection by EGCG in the present study because the oxidative stress was induced by an exogenous oxidant rather than by the leak of electrons from the mitochondrial respiratory chain.

The minimal effect of tBHP on succinate-stimulated respiration is in accord with our previous study $[25,26]$. This is also supported by previous findings that the activity of succinate dehydrogenase is disrupted by superoxide [27] but not by tBHP [24]. No effect of EGCG on succinate-dependent respiration is in accord with Weng et al. [46] who reported no inhibition by EGCG up to $60 \mu \mathrm{M}$ in normal isolated rat liver mitochondria. Their observation of major inhibition of all mitochondrial complexes in swelling mitochondria was not tested in our settings.

It was previously described that EGCG is able to induce $\mathrm{H}_{2} \mathrm{O}_{2}$ generation [22]. In the present study, we demonstrated oxygen consumption and hydrogen peroxide production in a mitochondria- and cell-free system. This is in accord with other authors who reported enhanced formation of hydrogen peroxide in the presence of EGCG [21]. Therefore, an additive toxic effect of tBHP and EGCG could be explained by an additive load of peroxides. By increasing hydrogen peroxide levels, EGCG was also shown to decrease cellular reduced glutathione [11].

Both methods used, isolated mitochondria and permeabilized hepatocytes, have their limitations. Permeabilized cells may have restricted diffusion of oxygen [47], whereas isolated mitochondria may be sensitized to permeability transition and ROS emission [48]. In the present study, both systems revealed similar effects of EGCG and tBHP on mitochondrial respiration. Similar results in permeabilized hepatocytes and in isolated mitochondria also suggest that the tested interval was too short to detect any changes in the stress-responsive Nrf2 pathway. This is in accord with a previous study [7] where the authors observed maximal upregulation of Nrf2-dependent genes after 6 hours of exposure to EGCG.

In conclusion, moderate nontoxic doses of EGCG were not able to protect rat liver mitochondria from $\mathrm{tBHP}$-induced mitochondrial dysfunction. An additive effect of EGCG and tBHP toxicity was observed when the highest concentration of $50 \mu \mathrm{M}$ EGCG was tested. 


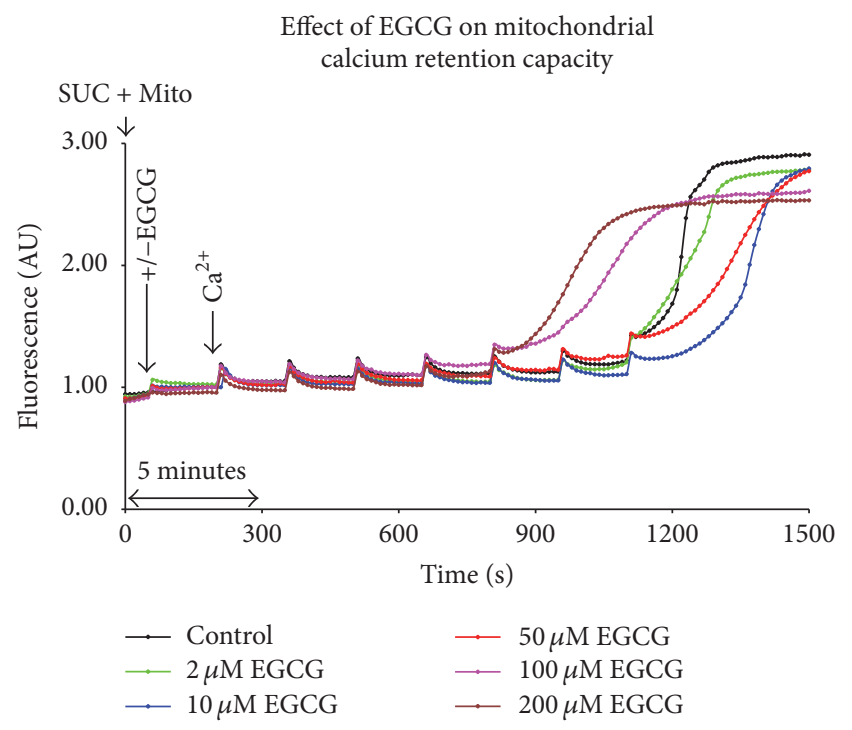

(a)

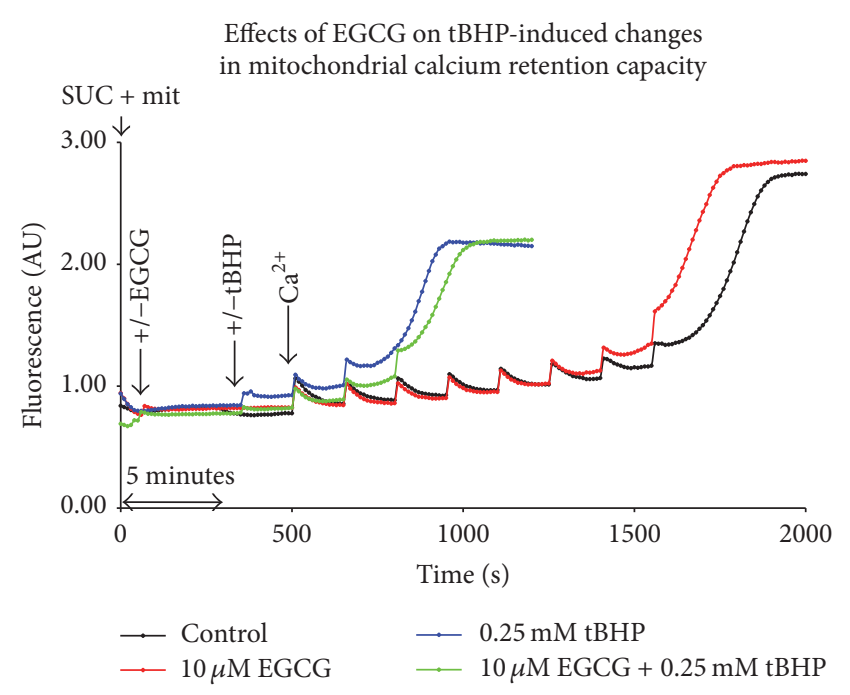

(b)

FIGURE 4: Representative curves of mitochondrial calcium retention capacity using Calcium Green after treatment with EGCG and/or tBHP. $\mathrm{CaCl}_{2}$ was added to increase its final concentration by $1.25 \mu \mathrm{M}$ upon every addition. (a) The effect of EGCG alone; (b) pretreatment with $10 \mu \mathrm{M}$ EGCG before the addition of $0.25 \mathrm{mM}$ tBHP. AU $=$ Arbitrary Units, SUC $=10 \mathrm{mM}$ succinate, and Mit $=$ mitochondria $(0.4 \mathrm{mg}$ protein per $\mathrm{mL})$.

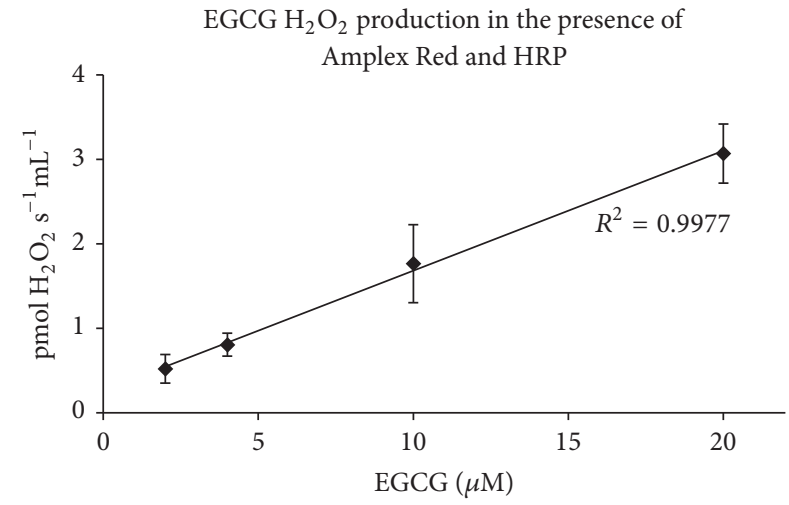

(a)

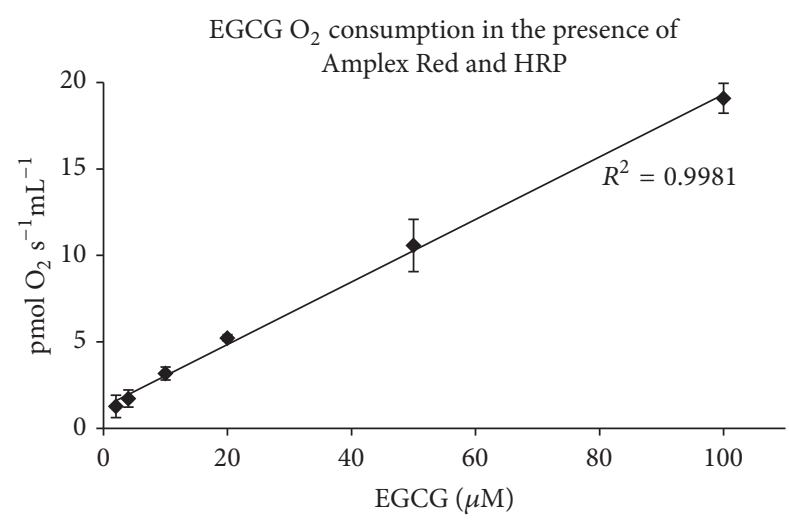

(b)

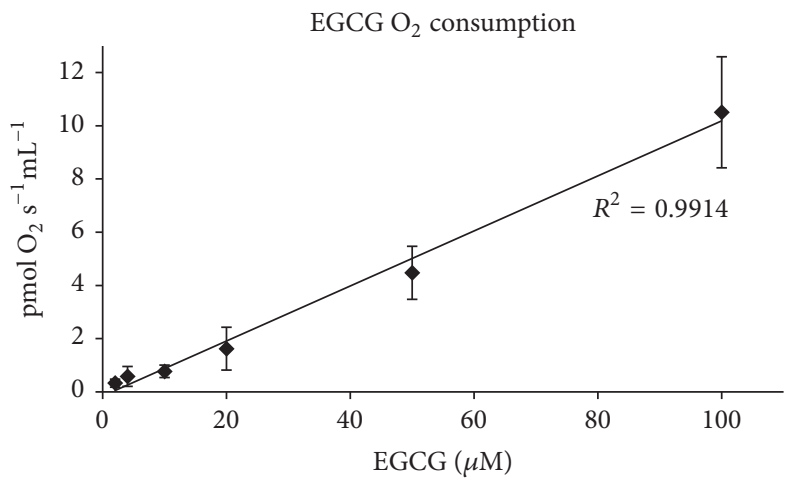

(c)

FIGURE 5: Background hydrogen peroxide production and oxygen consumption by EGCG. (a) $\mathrm{H}_{2} \mathrm{O}_{2}$ production detected by Amplex Red ( $n=$ 5-7); (b) oxygen consumption during $\mathrm{H}_{2} \mathrm{O}_{2}$ measurement $(n=7)$; (c) oxygen consumption in plain K-medium $(n=3-8)$. The background measurements in $\mathrm{a}$ and $\mathrm{b}$ were performed using two different fluorometry and oxygen sensors; measurements in (c) were performed using six different oxygen sensors. HRP: horseradish peroxidase. 


\section{Competing Interests}

The authors declare that there are no competing interests regarding the publication of this paper.

\section{Funding}

This study was supported by Grant PRVOUK P37/02.

\section{Acknowledgments}

Language of this manuscript was corrected by the American Journal Experts, certificate verification key 6807-7484-F24591E8-7593.

\section{References}

[1] K. Yoshino, Y. Hara, M. Sano, and I. Tomita, "Antioxidative effects of black tea theaflavins and thearubigin on lipid peroxidation of liver homogenates induced by tert-butyl hydroperoxide," Biological and Pharmaceutical Bulletin, vol. 17, no. 1, pp. 146-149, 1994.

[2] H.-K. Na and Y.-J. Surh, "Modulation of Nrf2-mediated antioxidant and detoxifying enzyme induction by the green tea polyphenol EGCG," Food and Chemical Toxicology, vol. 46, no. 4, pp. 1271-1278, 2008.

[3] Y. Wang, Y. Mei, D. Feng, and L. Xu, “(-)-Epigallocatechin3-gallate protects mice from concanavalin A-induced hepatitis through suppressing immune-mediated liver injury," Clinical and Experimental Immunology, vol. 145, no. 3, pp. 485-492, 2006.

[4] K. Sahin, M. Tuzcu, H. Gencoglu et al., "Epigallocatechin3 -gallate activates $\mathrm{Nrf} 2 / \mathrm{HO}-1$ signaling pathway in cisplatininduced nephrotoxicity in rats," Life Sciences, vol. 87, no. 7-8, pp. 240-245, 2010.

[5] G. L. Tipoe, T. M. Leung, E. C. Liong, T. Y. H. Lau, M. L. Fung, and A. A. Nanji, "Epigallocatechin-3-gallate (EGCG) reduces liver inflammation, oxidative stress and fibrosis in carbon tetrachloride $\left(\mathrm{CCl}_{4}\right)$-induced liver injury in mice," Toxicology, vol. 273, no. 1-3, pp. 45-52, 2010.

[6] J. D. Lambert and R. J. Elias, "The antioxidant and pro-oxidant activities of green tea polyphenols: a role in cancer prevention," Archives of Biochemistry and Biophysics, vol. 501, no. 1, pp. 6572, 2010.

[7] L. Romeo, M. Intrieri, V. D’Agata et al., "The major green tea polyphenol, (-)-epigallocatechin-3-gallate, induces heme oxygenase in rat neurons and acts as an effective neuroprotective agent against oxidative stress," The Journal of the American College of Nutrition, vol. 28, supplement 4, pp. 492S-499S, 2009.

[8] O. Kucera, V. Mezera, A. Moravcova et al., "In vitro toxicity of epigallocatechin gallate in rat liver mitochondria and hepatocytes," Oxidative Medicine and Cellular Longevity, vol. 2015, Article ID 476180, 10 pages, 2015.

[9] M. D. Brand, C. Affourtit, T. C. Esteves et al., "Mitochondrial superoxide: production, biological effects, and activation of uncoupling proteins," Free Radical Biology and Medicine, vol. 37, no. 6, pp. 755-767, 2004.

[10] S. A. Mookerjee, A. S. Divakaruni, M. Jastroch, and M. D. Brand, "Mitochondrial uncoupling and lifespan," Mechanisms of Ageing and Development, vol. 131, no. 7-8, pp. 463-472, 2010.
[11] G. Galati, A. Lin, A. M. Sultan, and P. J. O’Brien, “Cellular and in vivo hepatotoxicity caused by green tea phenolic acids and catechins," Free Radical Biology and Medicine, vol. 40, no. 4, pp. 570-580, 2006.

[12] M. Schmidt, H.-J. Schmitz, A. Baumgart et al., "Toxicity of green tea extracts and their constituents in rat hepatocytes in primary culture," Food and Chemical Toxicology, vol. 43, no. 2, pp. 307314, 2005.

[13] V. Mezera, O. Kucera, A. Moravcova, E. Peterova, and Z. Cervinkova, "The effect of epigallocatechin gallate on hepatocytes isolated from normal and partially hepatectomized rats," Canadian Journal of Physiology and Pharmacology, vol. 92, no. 6, pp. 512-517, 2014.

[14] W. Li, S. Nie, Q. Yu, and M. Y. Xie, “(-)-epigallocatechin-3gallate induces apoptosis of human hepatoma cells by mitochondrial pathways related to reactive oxygen species," Journal of Agricultural and Food Chemistry, vol. 57, no. 15, pp. 66856691, 2009.

[15] J. C. E. Serrano, H. Gonzalo-Benito, M. Jové et al., "Dietary intake of green tea polyphenols regulates insulin sensitivity with an increase in AMP-activated protein kinase $\alpha$ content and changes in mitochondrial respiratory complexes," Molecular Nutrition and Food Research, vol. 57, no. 3, pp. 459-470, 2013.

[16] Q. Meng, C. N. Velalar, and R. Ruan, "Regulating the age-related oxidative damage, mitochondrial integrity, and antioxidative enzyme activity in Fischer 344 rats by supplementation of the antioxidant epigallocatechin-3-gallate," Rejuvenation Research, vol. 11, no. 3, pp. 649-660, 2008.

[17] J. Liu, Y. Tang, Z. Feng, J. Liu, J. Liu, and J. Long, “(-)Epigallocatechin-3-gallate attenuated myocardial mitochondrial dysfunction and autophagy in diabetic Goto-Kakizaki rats," Free Radical Research, vol. 48, no. 8, pp. 898-906, 2014.

[18] S. Miltonprabu and S. Thangapandiyan, "Epigallocatechin gallate potentially attenuates Fluoride induced oxidative stress mediated cardiotoxicity and dyslipidemia in rats," Journal of Trace Elements in Medicine and Biology, vol. 29, pp. 321-335, 2015.

[19] J. A. G. Crispo, D. R. Ansell, M. Piche et al., "Protective effects of polyphenolic compounds on oxidative stress-induced cytotoxicity in PC12 cells," Canadian Journal of Physiology and Pharmacology, vol. 88, no. 4, pp. 429-438, 2010.

[20] T. Nakagawa and T. Yokozawa, "Direct scavenging of nitric oxide and superoxide by green tea," Food and Chemical Toxicology, vol. 40, no. 12, pp. 1745-1750, 2002.

[21] H. Nakagawa, K. Hasumi, J.-T. Woo, K. Nagai, and M. Wachi, "Generation of hydrogen peroxide primarily contributes to the induction of $\mathrm{Fe}(\mathrm{II})$-dependent apoptosis in Jurkat cells by (-)epigallocatechin gallate," Carcinogenesis, vol. 25, no. 9, pp. 15671574, 2004.

[22] L. H. Long, M. V. Clement, and B. Halliwell, "Artifacts in cell culture: Rapid generation of hydrogen peroxide on addition of $(-)$-epigallocatechin, (-)-epigallocatechin gallate, $(+)$-catechin, and quercetin to commonly used cell culture media," Biochemical and Biophysical Research Communications, vol. 273, no. 1, pp. 50-53, 2000.

[23] B. Chance, H. Sies, and A. Boveris, "Hydroperoxide metabolism in mammalian organs," Physiological Reviews, vol. 59, no. 3, pp. 527-605, 1979.

[24] H. Sies and K. M. Moss, "A role of mitochondrial glutathione peroxidase in modulating mitochondrial oxidations in liver," European Journal of Biochemistry, vol. 84, no. 2, pp. 377-383, 1978. 
[25] R. Endlicher, P. Křiváková, H. Rauchová, H. Nůsková, Z. Červinková, and Z. Drahota, "Peroxidative damage of mitochondrial respiration is substrate-dependent," Physiological Research, vol. 58, no. 5, pp. 685-692, 2009.

[26] Z. Drahota, P. Křiváková, Z. Červinková et al., “Tert-butyl hydroperoxide selectively inhibits mitochondrial respiratorychain enzymes in isolated rat hepatocytes," Physiological Research, vol. 54, no. 1, pp. 67-72, 2005.

[27] S. Melov, P. Coskun, M. Patel et al., "Mitochondrial disease in superoxide dismutase 2 mutant mice," Proceedings of the National Academy of Sciences of the United States of America, vol. 96, no. 3, pp. 846-851, 1999.

[28] C. Murakami, Y. Hirakawa, H. Inui, Y. Nakano, and H. Yoshida, "Effect of tea catechins on cellular lipid peroxidation and cytotoxicity in HepG2 cells," Bioscience, Biotechnology and Biochemistry, vol. 66, no. 7, pp. 1559-1562, 2002.

[29] A. Fernández-Iglesias, H. Quesada, S. Díaz et al., "DHA sensitizes $\mathrm{FaO}$ cells to tert-BHP-induced oxidative effects. Protective role of EGCG," Food and Chemical Toxicology, vol. 62, pp. 750757, 2013.

[30] L. Braud, L. Peyre, G. de-Sousa, M. Armand, R. Rahmani, and J.-M. Maixent, "Effect of brewing duration on the antioxidant and hepatoprotective abilities of tea phenolic and alkaloid compounds in a t-BHP oxidative stress-induced rat hepatocyte model," Molecules, vol. 20, no. 8, pp. 14985-15002, 2015.

[31] Z. Červinková, P. Křiváková, A. Lábajová et al., "Mechanisms participating in oxidative damage of isolated rat hepatocytes," Archives of Toxicology, vol. 83, no. 4, pp. 363-372, 2009.

[32] E. Bustamante, J. W. Soper, and P. L. Pedersen, "A high-yield preparative method for isolation of rat liver mitochondria," Analytical Biochemistry, vol. 80, no. 2, pp. 401-408, 1977.

[33] Z. Drahota, E. Palenickova, R. Endlicher et al., "Biguanides inhibit complex I, II and IV of rat liver mitochondria and modify their functional properties," Physiological Research, vol. 63, no. 1, pp. 1-11, 2014.

[34] M. M. Bradford, "A rapid and sensitive method for the quantitation of microgram quantities of protein utilizing the principle of protein-dye binding," Analytical Biochemistry, vol. 72, no. 1-2, pp. 248-254, 1976 .

[35] A. V. Kuznetsov, S. Schneeberger, R. Seiler et al., "Mitochondrial defects and heterogeneous cytochrome c release after cardiac cold ischemia and reperfusion," American Journal of Physiology-Heart and Circulatory Physiology, vol. 286, no. 5, pp. H1633-H1641, 2004.

[36] O. Kučera, R. Endlicher, T. Roušar et al., "The effect of tert-butyl hydroperoxide-induced oxidative stress on lean and steatotic rat hepatocytes in vitro," Oxidative Medicine and Cellular Longevity, vol. 2014, Article ID 752506, 12 pages, 2014.

[37] P. Staňková, O. Kučera, H. Lotková, T. Roušar, R. Endlicher, and Z. Červinková, "The toxic effect of thioacetamide on rat liver in vitro," Toxicology in Vitro, vol. 24, no. 8, pp. 2097-2103, 2010.

[38] K. E. O. Åkerman and M. K. F. Wikström, "Safranine as a probe of the mitochondrial membrane potential," FEBS Letters, vol. 68, no. 2, pp. 191-197, 1976.

[39] Z. Drahota, R. Endlicher, P. Staňková, D. Rychtrmoc, M. Milerová, and Z. Červinková, "Characterization of calcium, phosphate and peroxide interactions in activation of mitochondrial swelling using derivative of the swelling curves," Journal of Bioenergetics and Biomembranes, vol. 44, no. 3, pp. 309-315, 2012.
[40] F. Ichas, L. S. Jouaville, and J.-P. Mazat, "Mitochondria are excitable organelles capable of generating and conveying electrical and calcium signals," Cell, vol. 89, no. 7, pp. 1145-1153, 1997.

[41] E. Fontaine, O. Eriksson, F. Ichas, and P. Bernardi, "Regulation of the permeability transition pore in skeletal muscle mitochondria. Modulation by electron flow through the respiratory chain complex I," The Journal of Biological Chemistry, vol. 273, no. 20, pp. 12662-12668, 1998.

[42] G. Krumschnabel, M. Fontana-Ayoub, Z. Sumbalova et al., "Simultaneous high-resolution measurement of mitochondrial respiration and hydrogen peroxide production," Methods in Molecular Biology, vol. 1264, pp. 245-261, 2015.

[43] J. Serrano, M. Jové, J. Boada, M. J. Bellmunt, R. Pamplona, and M. Portero-Otín, "Dietary antioxidants interfere with Amplex Red-coupled-fluorescence assays," Biochemical and Biophysical Research Communications, vol. 388, no. 2, pp. 443-449, 2009.

[44] M. D. Brand and D. G. Nicholls, "Assessing mitochondrial dysfunction in cells," Biochemical Journal, vol. 435, no. 2, pp. 297-312, 2011.

[45] A. L. Orr, D. Ashok, M. R. Sarantos, T. Shi, R. E. Hughes, and M. D. Brand, "Inhibitors of ROS production by the ubiquinonebinding site of mitochondrial complex i identified by chemical screening," Free Radical Biology and Medicine, vol. 65, pp. 10471059, 2013

[46] Z. Weng, P. Zhou, W. F. Salminen et al., "Green tea epigallocatechin gallate binds to and inhibits respiratory complexes in swelling but not normal rat hepatic mitochondria," Biochemical and Biophysical Research Communications, vol. 443, no. 3, pp. 1097-1104, 2014.

[47] E. Gnaiger, "Capacity of oxidative phosphorylation in human skeletal muscle: new perspectives of mitochondrial physiology," International Journal of Biochemistry and Cell Biology, vol. 41, no. 10, pp. 1837-1845, 2009.

[48] R. T. Hepple, "Mitochondrial involvement and impact in aging skeletal muscle," Frontiers in Aging Neuroscience, vol. 6, article no. 211, 2014. 


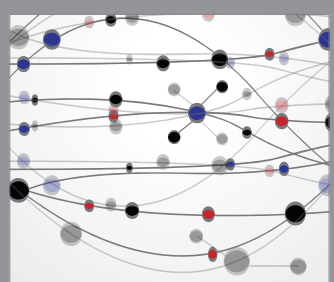

The Scientific World Journal
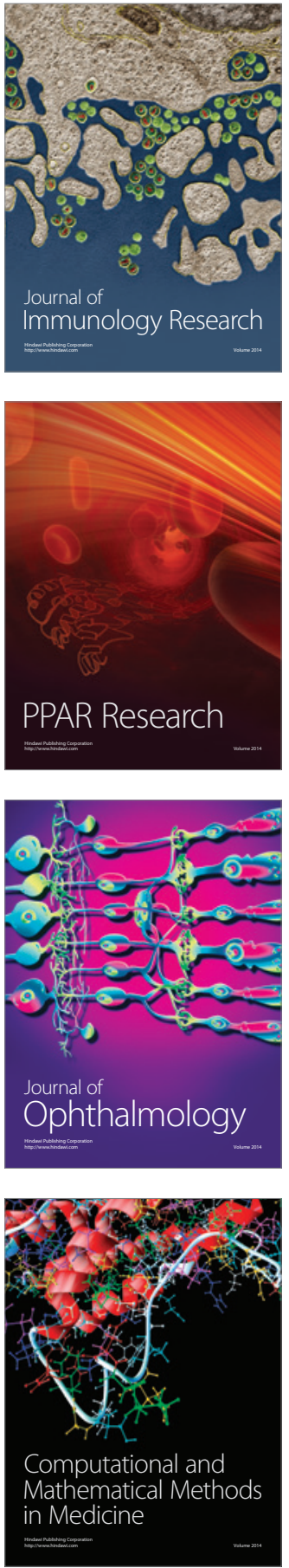

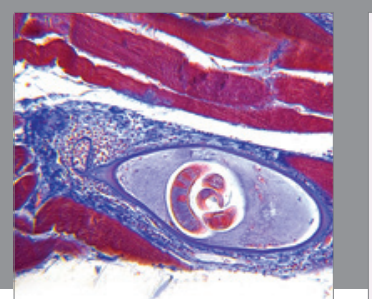

Gastroenterology Research and Practice

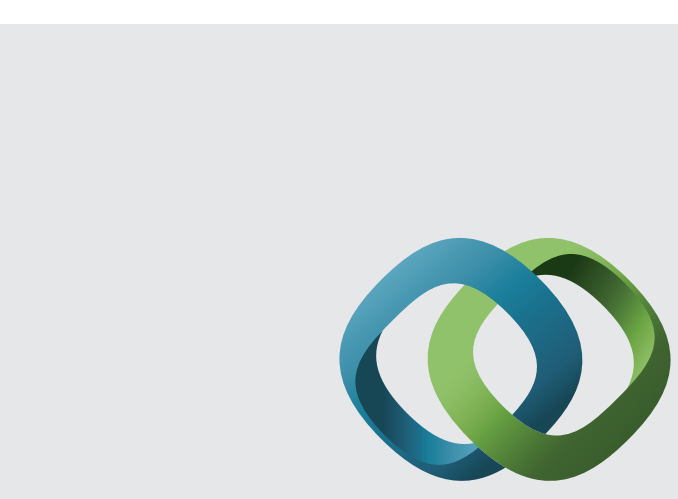

\section{Hindawi}

Submit your manuscripts at

http://www.hindawi.com
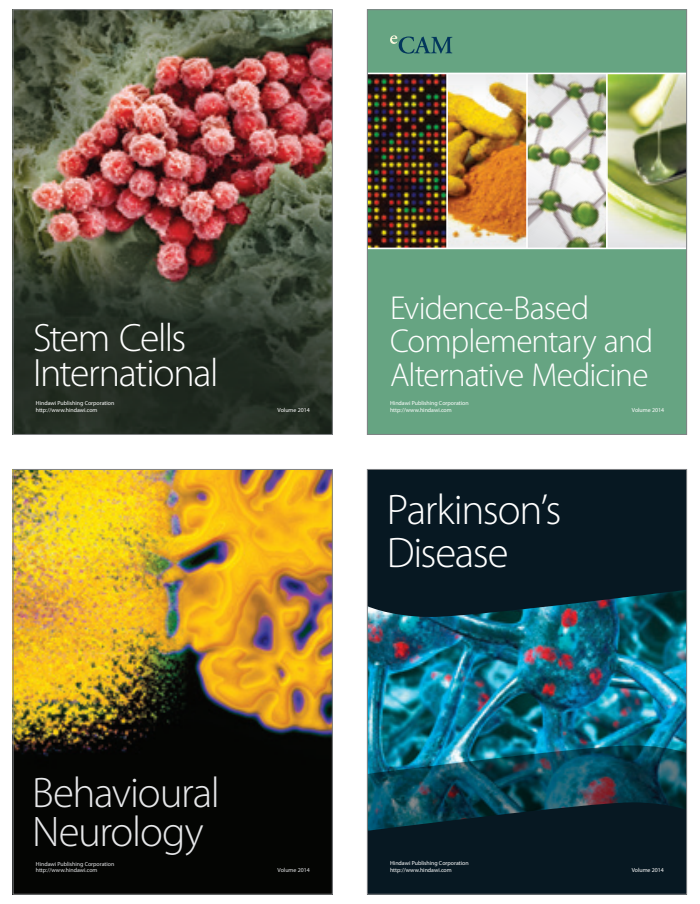
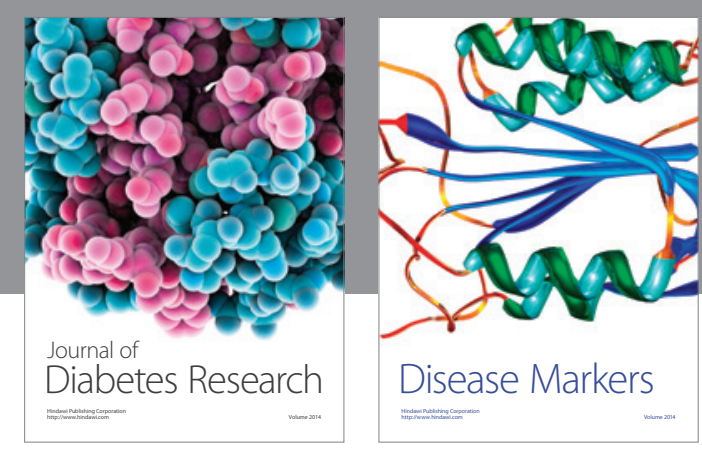

Disease Markers
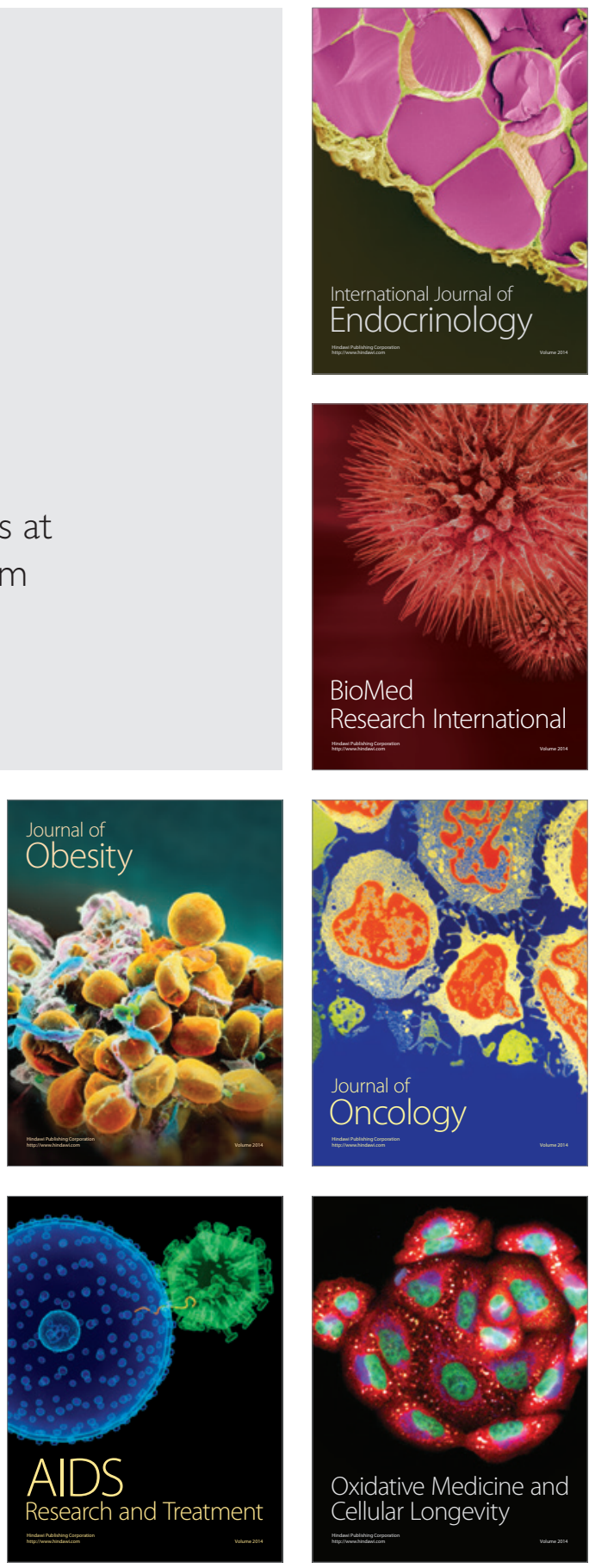